\title{
Movement and distribution of young bull sharks Carcharhinus leucas in a variable estuarine environment
}

\author{
Michelle R. Heupel ${ }^{1,2, *}$, Colin A. Simpfendorfer ${ }^{1,2}$ \\ ${ }^{1}$ Center for Shark Research, Mote Marine Laboratory, 1600 Ken Thompson Parkway, Sarasota, Florida 34236, USA \\ ${ }^{2}$ Present address: School of Earth and Environmental Sciences, James Cook University, Townsville, Queensland 4811, Australia
}

\begin{abstract}
The space utilization and distribution of young ( $<2$ yr old) bull sharks Carcharhinus leucas within a $27 \mathrm{~km}$ stretch of the Caloosahatchee River estuary in Southwest Florida was examined using an array of acoustic monitors to define influences of environmental variables. A total of 56 young sharks from 3 cohorts $(2003,2004,2005)$ were fitted with acoustic tags and monitored for up to $460 \mathrm{~d}$. Sharks did not remain within the estuary continuously, but on average approximately onethird were present at any one time from each cohort. Salinity and freshwater inflow showed greatest influence on shark distribution, with temperature appearing to play a limited role. Although individuals occurred in salinities from 0.1 to 34, electivity analysis indicated that they generally avoided areas with salinity $<7$ and had an affinity for areas with salinities from 7 to at least 20 . There were significant relationships between the mean location of a cohort within the estuary and salinity, with sharks occurring further up river when the river was more saline. These relationships were more pronounced for the youngest sharks, and strength of the relationship decreased with age. Since bull sharks are euryhaline, these results suggest that they may select environmental conditions via movement, possibly to reduce energetic costs associated with osmoregulation.
\end{abstract}

KEY WORDS: Carcharhinus leucas · Distribution · Habitat use · Salinity · Acoustic monitoring Resale or republication not permitted without written consent of the publisher

\section{INTRODUCTION}

The lower reaches of rivers are subject to considerable fluctuations in salinity, due to the competing influences of freshwater flows from the land and tidal flow from the ocean. Thus, resident animals can experience salinity regimes from totally freshwater to almost marine. Animals that live in these habitats have evolved a number of physiological strategies to deal with these changes in salinity. Sedentary animals must either be able to osmoregulate over a broad range of salinities, or perish. A large amount of research has been undertaken on the osmoregulatory abilities of sedentary animals, especially invertebrates, in changing salinity regimes (Maetz 1974, Stucchi-Zucchi \& Salomao 1998, Cheng et al. 2002). Mobile fauna, however, have an additional choice - to move with chang- ing environmental conditions to areas that may be more suitable. This may involve moving to remain in a constant salinity, or moving to allow time for osmoregulatory processes to adjust and then return to their normal location. Animals that move to remain in constant salinity may include those that have a poor ability to osmoregulate (i.e. that are stenohaline, either freshwater or marine invaders that occur in estuaries only during specific salinity regimes) and those that are attempting to maximize some benefit (e.g. increase prey availability, reduce predation or minimize energy expenditure on osmoregulation). This second group of animals may be physiologically euryhaline (in the laboratory), but appear to be more stenohaline because of their behavior. However, species that remain in the lower reaches of rivers over the long term must have good osmoregulatory abilities in a wide variety of 
salinities (i.e. must be euryhaline) because of relatively large seasonal changes in freshwater flow patterns in most systems.

There has been considerable study on the osmoregulatory abilities of teleost (Evans 1997, Kidder et al. 2006a,b) and elasmobranch fishes (Thorson et al. 1973, Piermarini \& Evans 1998, Pillans et al. 2006). However, the majority of this research is laboratory-based, providing an understanding of mechanisms and abilities in various species, but use of movement as a means of dealing with osmoregulatory stress is largely unstudied. To study movement of a teleost fish in response to salinity, Kidder (1997) introduced killifish (Fundulus heteroclitus) into a salinity gradient and found that they repeatedly selected a salinity that closely matched the osmolarity of their body fluids. This is despite the fact that under laboratory conditions they can osmoregulate over the full range of salinity from freshwater to sea water. Selecting such a salinity was thought to minimize the energy required to osmoregulate, and probably represented an optimal condition for growth. More recent studies on this species revealed that changing salinity did not affect oxygen uptake, but that a large change in osmotic flux due to salinity change must occur (Kidder et al. 2006a). The authors concluded that energy may be transferred from other processes to meet increased osmoregulatory needs. In a follow-up study, Kidder et al. (2006b) estimated that osmoregulation in seawater required 6 to $10 \%$ of the total energy budget of $F$. heteroclitus and that this energy demand was probably a driver for behavioral osmoregulation under some conditions.

Studies of elasmobranch movement patterns have demonstrated that movement is used to optimize energy allocation. For example, Matern et al. (2000) revealed that bat rays Myliobatis californica used behavioral thermoregulation to lower energetic demands and provide added energy by decreasing gastric evacuation rate. These conclusions were based on the movement of rays into warm shallow waters to feed followed by movement into cooler water to digest. Studies of several elasmobranch species including bat rays (Matern et al. 2000), leopard sharks (Ackerman et al. 2000) and sandbar sharks (Medved \& Marshall 1983, Wetherbee \& Rechisky 2000) all showed strong movement with tidal flow. This is suggested to conserve energy by allowing individuals to move via tidal transport rather than expend energy swimming. These examples reveal that sharks use movement to select specific habitats and reduce energetic demands.

In this study we examined the movement and distribution patterns of young bull sharks Carcharhinus leucas in relation to changes in a number of environmental parameters, with particular emphasis on salinity regime, within the Caloosahatchee River estuary in southwest Florida. Bull sharks are freshwater tolerant and have been reported from numerous freshwater systems around the world (Bass et al. 1973, Thomerson et al. 1977, Montoya \& Thorson 1982, Taniuchi et al. 1991, Pillans \& Franklin 2004). Preliminary evidence from fishing surveys within the Charlotte Harbor estuary (including the Caloosahatchee River) suggested that although juvenile bull sharks may occur in any salinity from fresh to marine, they show a preference for areas with salinities from $7-17$ at ages $<1$ yr (Simpfendorfer et al. 2005). Euryhaline and marine elasmobranchs are typically ureotelic, hyperosmotic regulators, meaning that they retain elevated osmotic pressure relative to their environment, usually via retention of urea and trimethylamine oxide. This strategy presumably allows euryhaline individuals to move between differing conditions. However, Pillans \& Franklin (2004) suggested that young C. leucas may be absent from marine environments due to an inability to regulate urea at levels observed in larger, fully marine individuals. Both Pillans \& Franklin (2004) and Simpfendorfer et al. (2005) suggested that telemetry research would be required to understand movement of $C$. leucas along salinity gradients. The purpose of this research was to use detailed information from an acoustic monitoring system to examine C. leucas movements in relation to environmental variables. The hypothesis presented is that salinity levels within the Caloosahatchee River affect the movements and distribution of young bull sharks. In addition, other physical factors that may influence movements within the estuary (e.g. temperature and freshwater inflow rates) were examined to determine if they also played a role in influencing the movements and distribution of juvenile bull sharks.

\section{MATERIALS AND METHODS}

Study area. The Caloosahatchee River is a dynamic habitat and a critical part of south Florida's wetlands, since it is the major source of freshwater to the Caloosahatchee River estuary and to the southern part of Charlotte Harbor, Florida (Fig. 1). The river connects Lake Okeechobee to the southwest coast of Florida and has been substantially altered over the past $100 \mathrm{yr}$ (Doering \& Chamberlain 1998). Habitat alterations include an artificial link to Lake Okeechobee, intricate canal systems connected to the main river channel, 2 locks to allow boat passage, and dams to regulate flow. These alterations have changed the freshwater flow in this system, resulting in large fluctuations in salinity in the downstream portion of the river (Flaig \& Capece 1998, SFWMD 2000). The South Florida Water Management District (SFWMD) manages the water level 


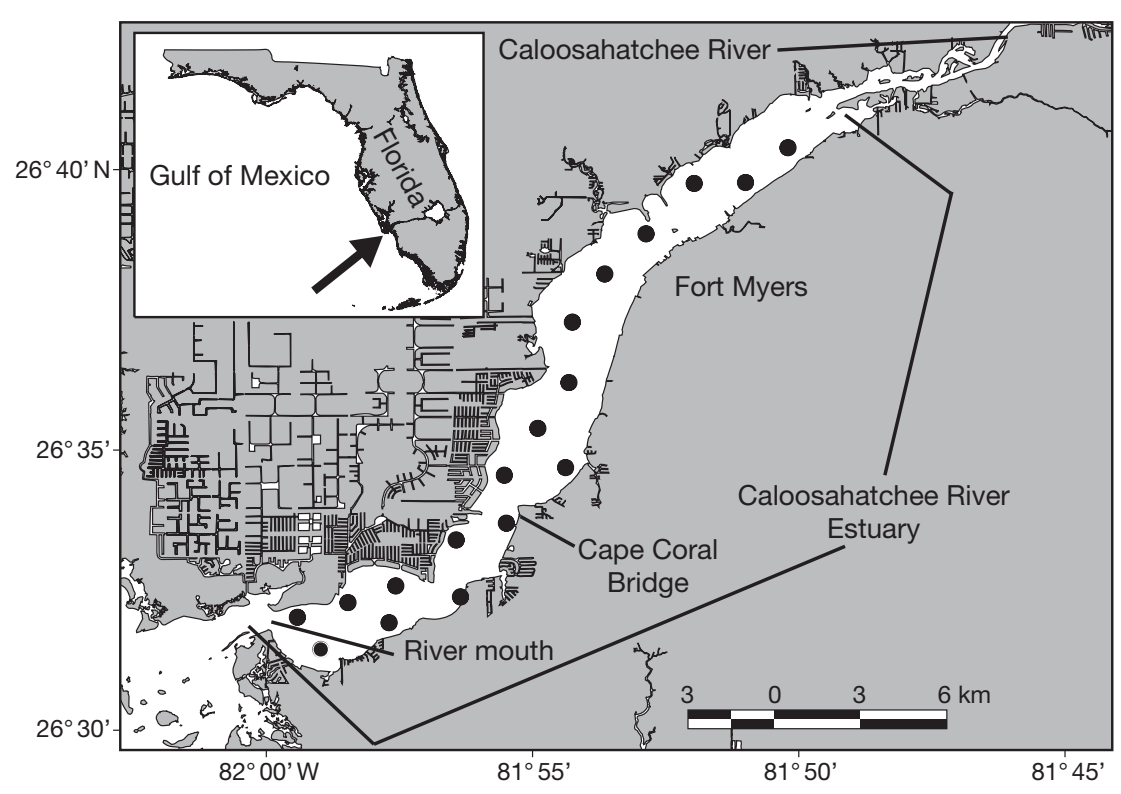

Fig. 1. The Caloosahatchee River estuary. Filled circles: locations of acoustic receiver stations. Inset: location of study site in Florida. Rectilinear markings (west of the river): canal systems connected to river channel

Field methods. A series of 20 VR2 acoustic receivers (Vemco/Amirix) were deployed within the study site (Fig. 1) to passively track the movement of sharks. Methods for deploying receivers have been described by Heupel \& Hueter (2001) and Simpfendorfer et al. (in press). Receivers were deployed in August of 2003 and were continuously present for the duration of the project. Receivers recorded the time, date and identity of sharks fitted with acoustic transmitters (see paragraph below) that swam within range of a unit. Deployed receivers were single frequency, omnidirectional units and had an approximate detection range of $600 \mathrm{~m}$ for V16 tags (M. R. Heupel unpubl. data). This detection range often allowed for sharks to be detected at $>1$ station simultaneously. The receiver array allowed sharks to be continuously monitored for most of the period they were present within

within Lake Okeechobee, controls flow rate through the Caloosahatchee River and continuously monitors conditions within the river.

The Caloosahatchee River has been well studied and provides a model for seasonal changes in environmental conditions in a human-impacted system (e.g. Doering \& Chamberlain 1998, Flaig \& Capece 1998). During the dry winter months the river ranges from mesohaline (salinity ranging from 5 to 18 ) to polyhaline (salinity range of 18 to 30). Once summer rainfall levels increase or freshwater is drained off Lake Okeechobee, the dynamics of the river change to become almost exclusively oligohaline (salinity range 0 to 5 ) with no tidal influence. Discharges of freshwater through the river vary greatly throughout the year and can reach as much as $480 \mathrm{~m}^{3} \mathrm{~s}^{-1}$ (SFWMD 2000). High flow rates typically occur during the late summer months (i.e. August to September) and cause swift declines in salinity within the estuary. After flows decrease, the river returns to a mesohaline state. Vertical stratification is present in the river during periods of moderate flow, with a salt wedge extending several kilometers into the estuary.

This study was completed in the estuarine portion of the river (Fig. 1) and encompassed approximately $27 \mathrm{~km}$ of habitat. Upper reaches of the estuary have natural shoreline and native vegetation (primarily red mangrove Rhizophora mangle). Closer to the mouth the habitat has been largely altered by urbanization as evidenced by extensive canal developments (Fig. 1) and shoreline modifications. the study area. Data were downloaded from receiver stations approximately once per month, and any required maintenance (e.g. cleaning, battery change) was also conducted at these times. Each time receivers were downloaded, the surface and bottom temperature, salinity and dissolved oxygen were measured using a water quality meter (YSI 85).

Sharks were captured by longline fishing, weighed, measured, tagged with a single barb plastic dart tag, and surgically fitted with a Vemco RCODE $16 \times 65 \mathrm{~mm}$ transmitter. Longlines consisted of an $800 \mathrm{~m}$ long bottom-set mainline consisting of $8 \mathrm{~mm}$ braided nylon rope anchored at both ends. Gangions were constructed of $1 \mathrm{~m}$ of $5 \mathrm{~mm}$ braided nylon cord and $1 \mathrm{~m}$ of stainless steel wire leader. Mustad tuna circle hooks ranging in size from 12/0 to 16/0 were baited with frozen mullet Mugil cephalus and fresh catfish Arius felis. Longlines were set for periods from $30 \mathrm{~min}$ to $2 \mathrm{~h}$, with most set for approximately $1.5 \mathrm{~h}$. All captured individuals were neonate or young-of-the-year (based on the presence of umbilical scars or size) with sizes ranging from 68 to $96 \mathrm{~cm}$ total length (mean: $80.3 \pm$ $1.1 \mathrm{~cm} \mathrm{SE}$ ). Transmitters were coded with a unique pulse series for each shark, operated on $69.0 \mathrm{kHz}$ at randomly spaced intervals between 45 and $75 \mathrm{~s}$, and had a battery life of at least 18 mo. Random signal transmission times prevented $>1$ signal continuously overlapping and blocking detection by a receiver station. Over $3 \mathrm{yr}, 56$ bull sharks were monitored in the river (2003-18: 8 female, 10 male; 2004-18: 7 female, 11 male; 2005 - 20: 10 female and 10 male). 
Data analysis. Presence of all tagged sharks was assessed on a daily basis, with individuals considered present in the study site if $>1$ signal was detected on any receiver in the array on a given day. Presence histories were plotted by day to provide a visually interpretable timeline of animals present in the study site (M. R. Heupel unpubl. data), and the number of days that individuals were present in the study site was calculated. The number of sharks present each day for each cohort was calculated and compared to daily freshwater inflow (flow through the Franklin Locks, upstream of the study site; river distance $=35 \mathrm{~km}$ from the river mouth) and salinity (mean of the continuously measured value at the Cape Coral Bridge (river distance $=10.5 \mathrm{~km}$ ) obtained from the SFWMD. Comparisons between number of individuals present and salinity or freshwater inflow rate were completed for the first 15 mo after release to ensure periods of potential transmitter failure (after $18 \mathrm{mo}$ ) were not included. The salinity at Cape Coral was used as an index of the salinity regime present in the river on each day, and like all salinity measuring stations on the river was negatively correlated with freshwater inflow $\left(\mathrm{R}^{2}=\right.$ 0.591, $\mathrm{p}<0.0001)$. Variability in salinity within the estuary was highly dependent on freshwater inflow and rainfall amounts. Differences in salinity between the mouth and the top of the study site ranged from 0.1 to 20.4, depending on conditions, with largest differences when freshwater inflow was lowest.

The location of sharks within the estuary was estimated every 30 min using the river distance algorithm described by Simpfendorfer et al. (in press). This algorithm used data from the receiver array to estimate the linear distance between the center of activity of each individual and the river mouth for each $30 \mathrm{~min}$ period of the day. Thus the location of individuals within the estuary was estimated on a linear scale. The number of transmitter detections was tallied into $1 \mathrm{~km}$ bins and the frequencies compared between cohorts using a $G$ test. The $30 \mathrm{~min}$ position estimates were used to generate daily minimum, maximum and mean river distances for individual sharks and cohorts.

To investigate physical factors that may have influenced the location of sharks within the estuary, the mean river distance of each cohort on days when equipment was downloaded (and hence physical parameters recorded) was compared to the temperature and salinity recorded at the station closest to the river mouth. Data were compared to a single station, as values were highly correlated between stations. Regression analysis was used to determine if there were significant relationships between river distance and each of these parameters for individual cohorts and combined cohorts.
To investigate the relationship between shark locations and salinity in more detail, the daily mean river distances for each cohort were compared to daily freshwater inflow and mean salinity data from the SFWMD Cape Coral station. Shark location data were divided into 2 groups: (1) those from release until the following May (age <1 yr) and (2) those at liberty after the May following release (age $>1$ yr). Regression analysis was used to examine the relationships between River Distance and Salinity, and River Distance and Freshwater Inflow. In addition, a generalized linear model (GLM) was used to investigate the relationships between daily Mean River Distance and factors that were considered to potentially influence movements (Cohort, Year, Age, Month, Salinity and Freshwater Inflow). The saturated GLM was Mean River Distance $\sim$ Cohort + Year + Salinity + Flow + Age + Month + Salinity $\times$ Flow. Daily temperature data were not available for inclusion in the model, but Month was correlated with temperature and thus incorporated temperature information into the model. Factors and interaction terms were removed using a backwards stepwise procedure based on the Akaike Information Criterion (Akaike 1973). The final model identified factors and interaction terms that had a statistically significant influence on the location of sharks within the river.

Electivity. To determine if juvenile Carcharhinus leucas exhibited affinity for or avoidance of specific salinity regimes within the river, the salinities in which tagged individuals occurred were compared to those available in the river using Chesson's $\alpha$ (Chesson 1978):

$$
\alpha=\left(r_{i} / p_{i}\right) / \sum\left(r_{i} / p_{i}\right)
$$

where $r_{i}$ is the proportion of time an individual spent in salinity $i$ and $p_{i}$ is the proportion of salinity $i$ available in the estuary. The value of $\alpha$ can range from 0 to 1 , with a value of $1 /$ (number of categories) indicating no electivity or avoidance. The salinity for a given location within the river was estimated using a multiple linear regression relating the salinity to the location within the estuary (river distance - see 'Data analysis' above) and freshwater inflow into the estuary through the Franklin Locks. This relationship was calculated from monthly salinity values measured at each of the receiver stations and the flow records for the Franklin Locks from the SFWMD (P. Doering pers. comm.). The $3 \mathrm{~d}$ total flow at the Franklin Locks $(1,3$, and $10 \mathrm{~d}$ total flows were evaluated and the 3 day flows produced the best results) on each of the download days, the location of the receiver stations within the estuary and the salinity measured at each of the stations was then evaluated using multiple linear regression, and produced the relationship: Salinity $=48.593-4.0337 \times$ $\ln ($ Flow $)-0.4513 \times$ Distance $\left(\mathrm{R}^{2}=0.747, \mathrm{p}<0.0001\right)$. 
This relationship was then used to determine the mean daily salinity at the location of each tagged shark. Shark locations were determined using the mean daily location estimated by the positioning data (see river distance algorithm information in 'Data analysis', above). The salinity values across all sharks and all days were then tallied into 2 unit bins. Salinity values within the river were calculated by estimating the daily salinity at $1 \mathrm{~km}$ intervals along the length of the estuary covered by the array ( $\mathrm{Km} 2$ to 27 ) using the same relationship. Available salinities were determined for individual sharks only for periods when they were present in the river, and then tallied across all sharks. Tallies were calculated separately for each cohort. Tallies of salinities in which sharks occurred and salinities that were available were converted to proportions and the electivity for each salinity (0 to 30 ) calculated. Since values of $\alpha$ that corresponded to electivity varied between years (based on changes in environmental conditions), values were standardized by subtracting the value of $1 /$ (number of categories).

\section{RESULTS}

\section{Shark presence}

A total of 56 neonate and young-of-the-year bull sharks were released within the Caloosahatchee River estuary from 2003 to 2005. Sharks were released into the study site during August $2003(\mathrm{n}=18)$; July $(\mathrm{n}=12)$, September $(\mathrm{n}=2)$ and November $(\mathrm{n}=4) 2004$; and in June $(n=20)$ 2005. Monitored Carcharhinus leucas were present within the study site for periods of 2 to $460 \mathrm{~d}$ $($ mean $=199 \mathrm{~d})$. Individuals were present during all seasons of the year and were exposed to temperatures ranging from 14.4 to $32.4^{\circ} \mathrm{C}$ (mean $=24.9^{\circ} \mathrm{C}$, median $=$ $25.8^{\circ} \mathrm{C}$ ). During this period, salinity within the study site ranged from 0.1 to 34.0 (mean $=7.7$, median $=5.1$ ).

The proportion of the monitored population (number of individuals fitted with transmitters in a given year) that was present within the study site through time was examined to define patterns in occurrence. Minimal mortality was observed in any monitored individuals during the study period, so presence was based on the number of individuals present in the river. For the 2003 cohort the proportion of individuals present within the estuary ranged from 0 to $83 \%$ per day (mean $=30 \%$, median $=33 \%$ ). The number of individuals present varied through time, with highest proportions present during October to December 2003 and lowest proportions present during September of 2003 and 2004 (Fig. 2a). For the 2004 cohort the proportion of individuals present ranged from 0 to $67 \%$ per day (mean = $33 \%$, median $=39 \%$ ). The proportion of individuals
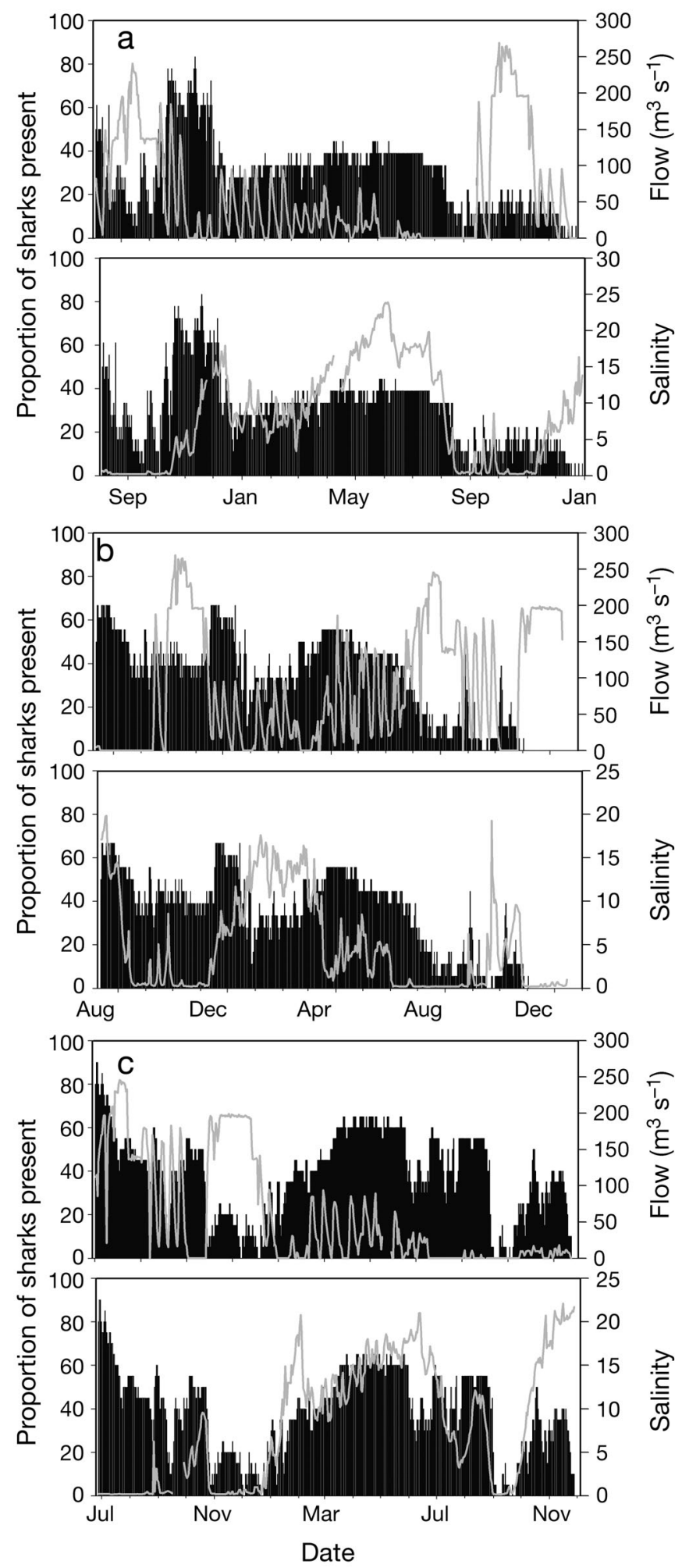

Fig. 2. Carcharhinus leucas. Presence of bull sharks fitted with acoustic tags from (a) the 2003 cohort, (b) the 2004 cohort, and (c) the 2005 cohort, within the Caloosahatchee River estuary relative to freshwater inflow (top panels) and salinity regime (bottom panels). Vertical bars: shark presence; grey line: environmental parameters 
present in 2004 was less variable than in 2003, with highest numbers present in July and November 2004 and lowest numbers present in December 2004 and July to August 2005 (Fig. 2b). In the 2005 cohort the proportion of individuals present ranged from 0 to $90 \%$ per day $($ mean $=39 \%$, median $=40 \%$ ). Presence was highest in July 2005 and April to June 2006. Lowest proportions were in November to December 2005 and September to October 2006 (Fig. 2c). Periods when flows were increasing and salinities falling corresponded to those when the proportion of sharks within the study area were decreasing, and periods when flow was declining and salinity increasing corresponded to those when the proportion was increasing (Fig. 2a-c).

\section{Distribution and environmental parameters}

The distribution of individuals along the river showed that in all cohorts sharks spent the majority of time within $11 \mathrm{~km}$ of the mouth (Fig. 3): $63 \%$ of detections in 2003, 45\% in 2004 and $71 \%$ in 2005 were within this region, with the proportion of detections by river kilometer significantly different between years $\left(\chi^{2}=35227.86, \mathrm{df}=48, \mathrm{p}<0.0001\right)$. One reason for this difference may be that the majority of the 2004 cohort was captured and fitted with transmitters farther up river than in 2003 and 2005. As a result of capture farther up river, the 2004 cohort had more detections upriver after release than other years. Soon after release most individuals in 2004 moved toward the river mouth, more consistent with locations recorded for cohorts in 2003 and 2005 during that time period.

Examination of the mean river distance on days when data were downloaded and environmental parameters were recorded at each receiver station showed a distinct pattern (Fig. 4). Comparison of mean river distance to salinity revealed significant correlations and positive slopes for all 3 cohorts $\left(2003: \mathrm{R}^{2}=0.855\right.$, slope $=0.495, \mathrm{p}<0.0001 ; 2004: \mathrm{R}^{2}=0.882$, slope $=$ $0.543, \mathrm{p}<0.0001 ; 2005: \mathrm{R}^{2}=0.815$, slope $=1.056, \mathrm{p}=$ 0.0015). The slope of the relationship between water temperature and river distance in 2003 and 2005 was not significant (2003: $\mathrm{R}^{2}=0.744$, slope $=-0.402, \mathrm{p}=$ $0.104 ; 2005: R^{2}=0.980$, slope $\left.=0.031, p=0.866\right)$. In 2004, however, there was a significant negative relationship $\left(R^{2}=0.826\right.$, slope $\left.=-0.742, p=0.005\right)$, suggesting that temperature may have influenced river location in that year. The consistent relationship between mean river distance and salinity, compared to the inconsistent relationship to temperature, suggests that salinity may have influenced the movement patterns of sharks more than temperature.

Detailed analysis of shark distribution within the estuary in relation to daily salinity and freshwater inflow levels revealed a close relationship between river salinity and shark location for all 3 cohorts, suggesting behavior within cohorts was not highly variable (Fig. 5). However, this trend appeared less consistent for the 2004 cohort. Examination of location in relation to salinity from date of release to May of the

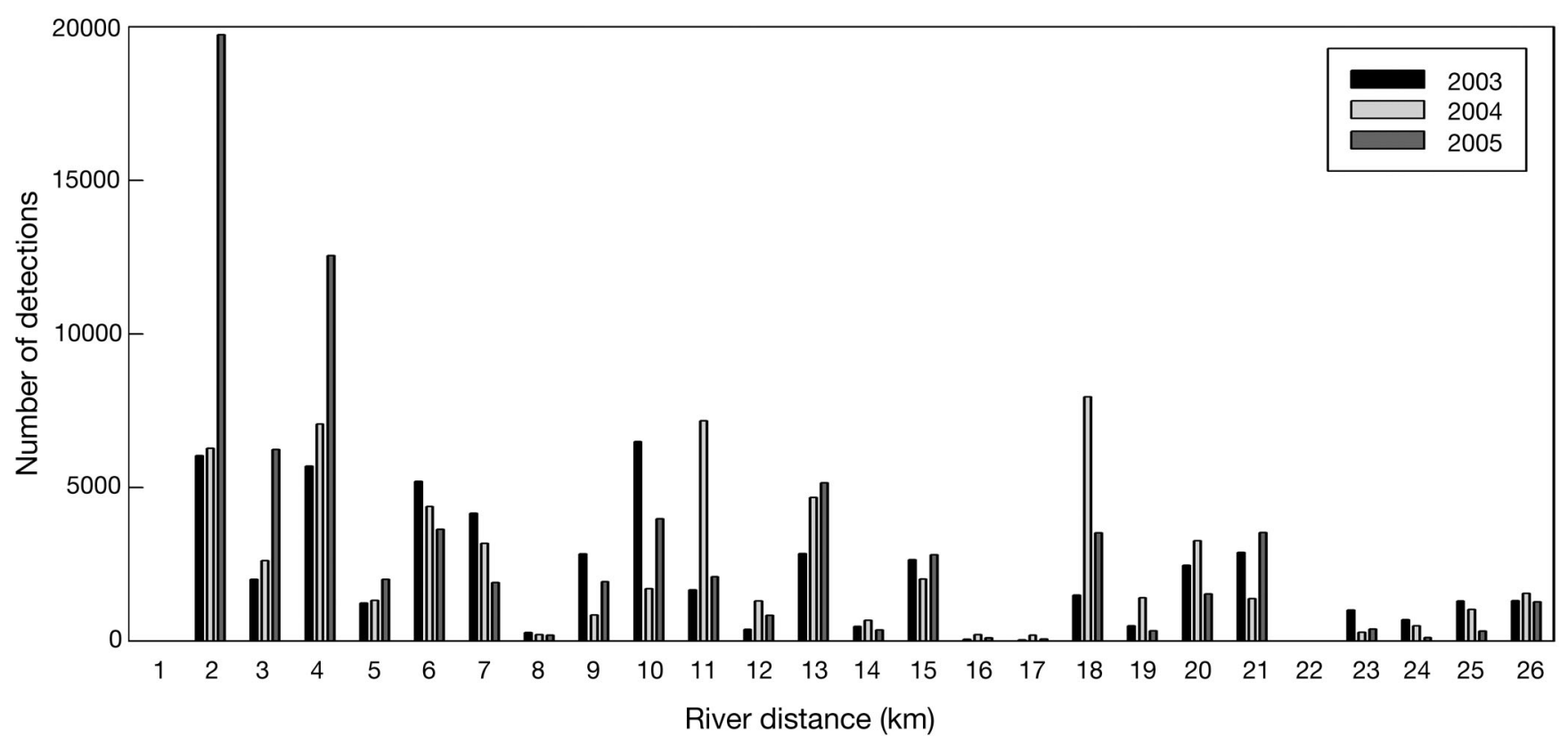

Fig. 3. Carcharhinus leucas. Distribution of the 2003 to 2005 bull shark cohorts amongst $1 \mathrm{~km}$ sections of the Caloosahatchee River estuary. Location calculated using a linear mean-position algorithm 


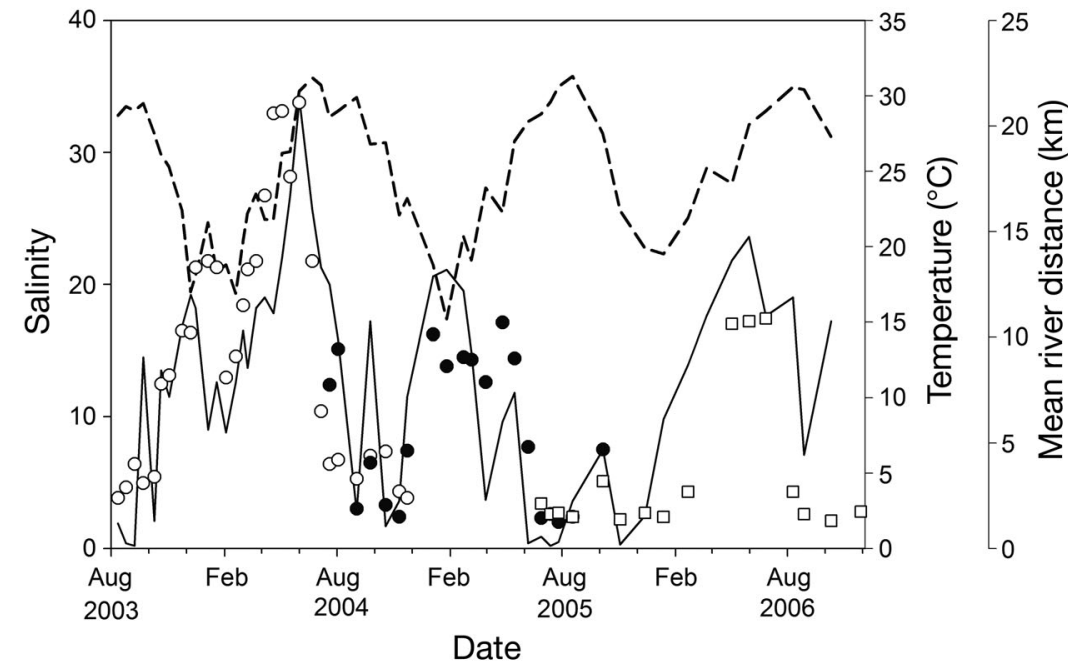

Fig. 4. Carcharhinus leucas. Mean river location of bull sharks from the 2003 (open circles), 2004 (filled circles) and 2005 (open squares) cohorts within the Caloosahatchee River estuary on days that equipment was downloaded, and corresponding temperature (dashed line) and salinity (solid line) at the acoustic receiver station closest to the river mouth

following year (i.e. $<1$ yr old sharks) showed a strong significant relationship for all 3 cohorts $\left(2003: \mathrm{R}^{2}=\right.$ 0.930, slope $=0.077, \mathrm{p}<0.0001 ; 2004: \mathrm{R}^{2}=0.888$, slope $=0.599, \mathrm{p}<0.0001 ; 2005: \mathrm{R}^{2}=0.778$, slope $=$ $0.463, \mathrm{p}<0.0001$ ) while examination after the May following release (i.e. 1 yr old sharks) revealed slightly lower correlations for the 2004 cohort $\left(2003: \mathrm{R}^{2}=0.900\right.$, slope $=0.677, \mathrm{p}<0.0001 ; 2004: \mathrm{R}^{2}=0.807$, slope $=$ $0.562, \mathrm{p}=0.002 ; 2005: \mathrm{R}^{2}=0.757$, slope $=0.467, \mathrm{p}<$ $0.0001)$. This suggested that movements of young-ofthe-year animals were more influenced by salinity than animals older than $1 \mathrm{yr}$.

There was an inverse relationship between shark location and freshwater inflow rate for 2003 and 2005 cohorts (Fig. 6a,e), with sharks occurring throughout the study area at low flow rates $\left(<57 \mathrm{~m}^{3} \mathrm{~s}^{-1}\right)$, but only near the mouth at flows $>113 \mathrm{~m}^{3} \mathrm{~s}^{-1}$ (Fig. 6b,f). This relationship existed when animals were both $<1$ and $>1$ yr old. Conversely, there was no obvious relationship between flow rate and shark locations for the 2004 cohort (Fig. 6c,d). Examination of the relationship when sharks were $<1$ yr old showed a similar pattern in 2004 to that of the 2003 and 2005 cohorts $\left(2003: R^{2}=0.763\right.$, slope $=-0.0011, \mathrm{p}<0.0001 ; 2004: \mathrm{R}^{2}=0.826$, slope $=$ $-0.0008, \mathrm{p}<0.0001 ; 2005: \mathrm{R}^{2}=0.668$, slope $=-0.0006$, $\mathrm{p}<0.0001$ ) (Fig. 6b,f), while there appeared to be no relationship between flow and location for sharks $>1 \mathrm{yr}$ old (2003: $\mathrm{R}^{2}=0.691$, slope $=-0.0009, \mathrm{p}<0.0001 ; 2004$ : $\mathrm{R}^{2}=0.796$, slope $=0.0002, \mathrm{p}=0.379 ; 2005: \mathrm{R}^{2}=0.749$, slope $=-0.0076, p<0.0001$ ) (Fig. 6d). This suggests that as individuals aged, the influence of flow (or factors correlated with flow) had less effect on movements.
The final model indicated by the GLM analysis was Mean River Distance $\sim$ Cohort + Year + Salinity + Flow + Month + Salinity $\times$ Flow (Table 1$)$. The model indicated that the location of sharks was different between Cohort and Year. Age was not significant and dropped from the model, suggesting that the distribution of sharks did not change as they aged. Salinity and Flow were both significant influences on location, and the interaction between these factors was also significant. The interaction between these 2 factors suggests they act separately on bull sharks distribution in a relatively complex way.

\section{Electivity}

Electivity analysis showed that young bull sharks spent the majority of their time in areas with salinities between 5 and 20, while the available environment was mostly from 0 to 16 , with only $10.6 \%$ having a salinity of $>20$ (Fig. $7 \mathrm{a}$ ). Electivity values across the range of salinities showed similarities between cohorts (Fig. 7b). Electivities indicated strong avoidance of low salinities, followed by increasing values to relatively strong affinity for salinities around 12. The salinities at which electivity values switched from avoidance to affinity ranged from 5 for the 2004 cohort to 10 for the 2005 cohort, while for data from all 3 years combined it was 8 . At salinities between 12 and 20, electivities for all cohorts mostly indicated affinity, although the 2003 and 2005 cohorts did dip into slight avoidance at some salinities. At salinities > 20 electivities became more variable, probably reflecting the limited data available at these levels. Electivities were also calculated separately for each age class $(0+$ and $1+)$, but these did not differ substantially from the combined results.

Table 1. Analysis of deviance for final generalised linear model for shark location

\begin{tabular}{|lrrr|}
\hline Term & df & Deviance & $\begin{array}{r}\text { Residual } \\
\text { deviance }\end{array}$ \\
\hline Null model & & & 413814 \\
Cohort & 2 & 13439 & 400375 \\
Year & 3 & 53223 & 347151 \\
Month & 11 & 100633 & 246519 \\
Salinity & 1 & 39434 & 207084 \\
$\ln ($ Flow) & 1 & 204296 & 2788 \\
$\ln ($ Flow) $\times$ Salinity & 1 & 44 & 2744 \\
\hline
\end{tabular}



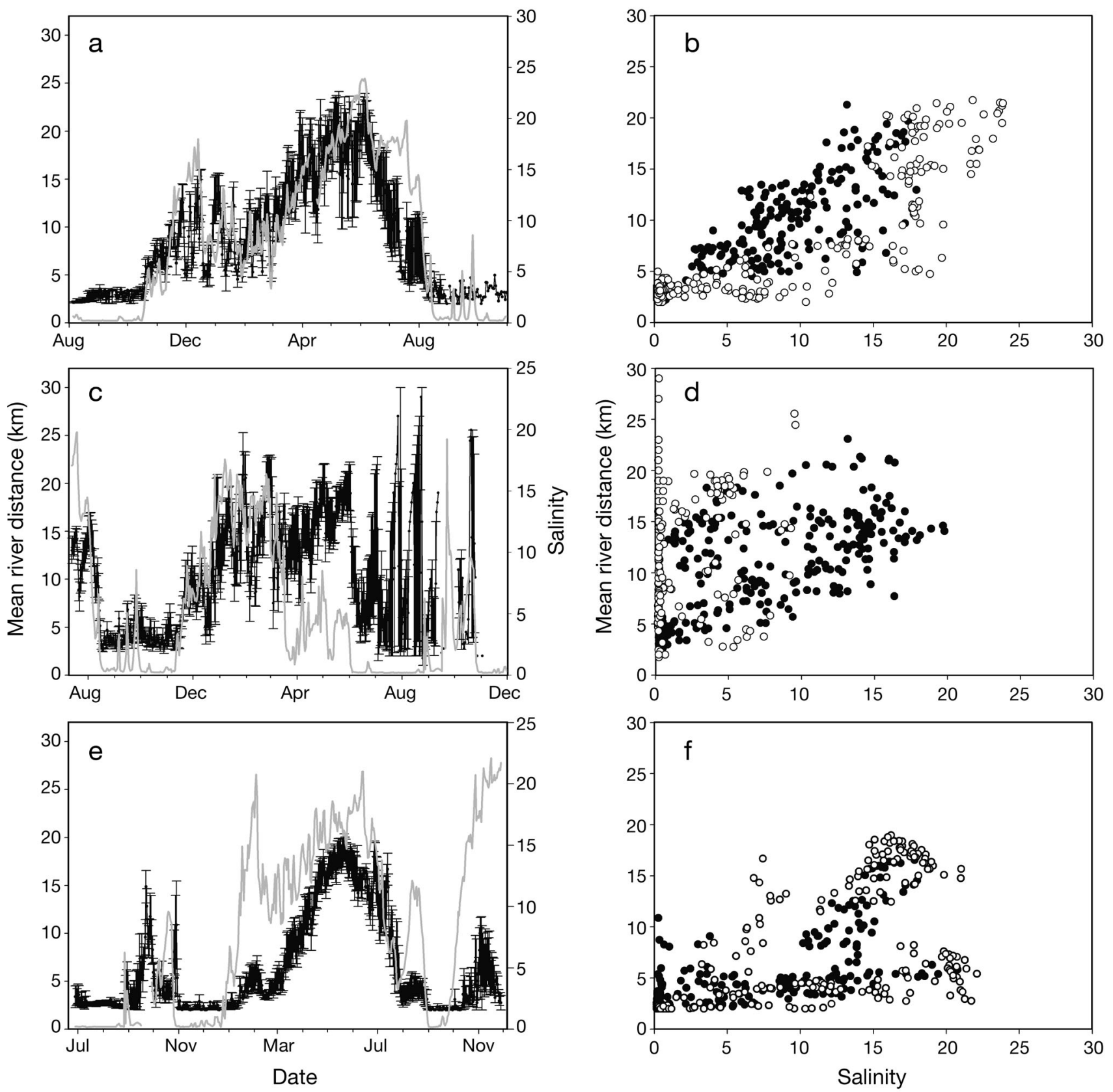

Fig. 5. Carcharhinus leucas. Relationship between salinity and distribution of acoustically tagged bull sharks from the (a,b) 2003, (c,d) 2004 and (e,f) 2005 cohorts within the Caloosahatchee River estuary. Time series plots (a,c,e) - grey line: salinity; points (largely hidden by error bars): mean river location; error bars: minimum and maximum extent of a cohort. Scatter plots $(\mathrm{b}, \mathrm{d}, \mathrm{f})$ show daily mean river location and salinity for sharks $<1$ yr old (filled circles) and $>1$ yr old (open circles)

\section{DISCUSSION}

\section{Shark presence}

This study demonstrated that young Carcharhinus leucas use estuarine nurseries for long periods. Most individuals utilised the Caloosahatchee River estuary for at least 18 mo with minimal mortality in the monitored population. Not all individuals remained within the sys- tem, but data indicated that on any day up to $18 \mathrm{mo}$ after release, at least $30 \%$ of each of the 3 cohorts monitored were present within the river. Decrease in numbers monitored towards the end of this period was the result of individuals leaving the system and due to the battery life of transmitters, which was 18 to 24 mo. In addition, variations in the proportions of animals within the system appeared to correspond to changes in salinity and freshwater inflow. Periods of high flow and low 

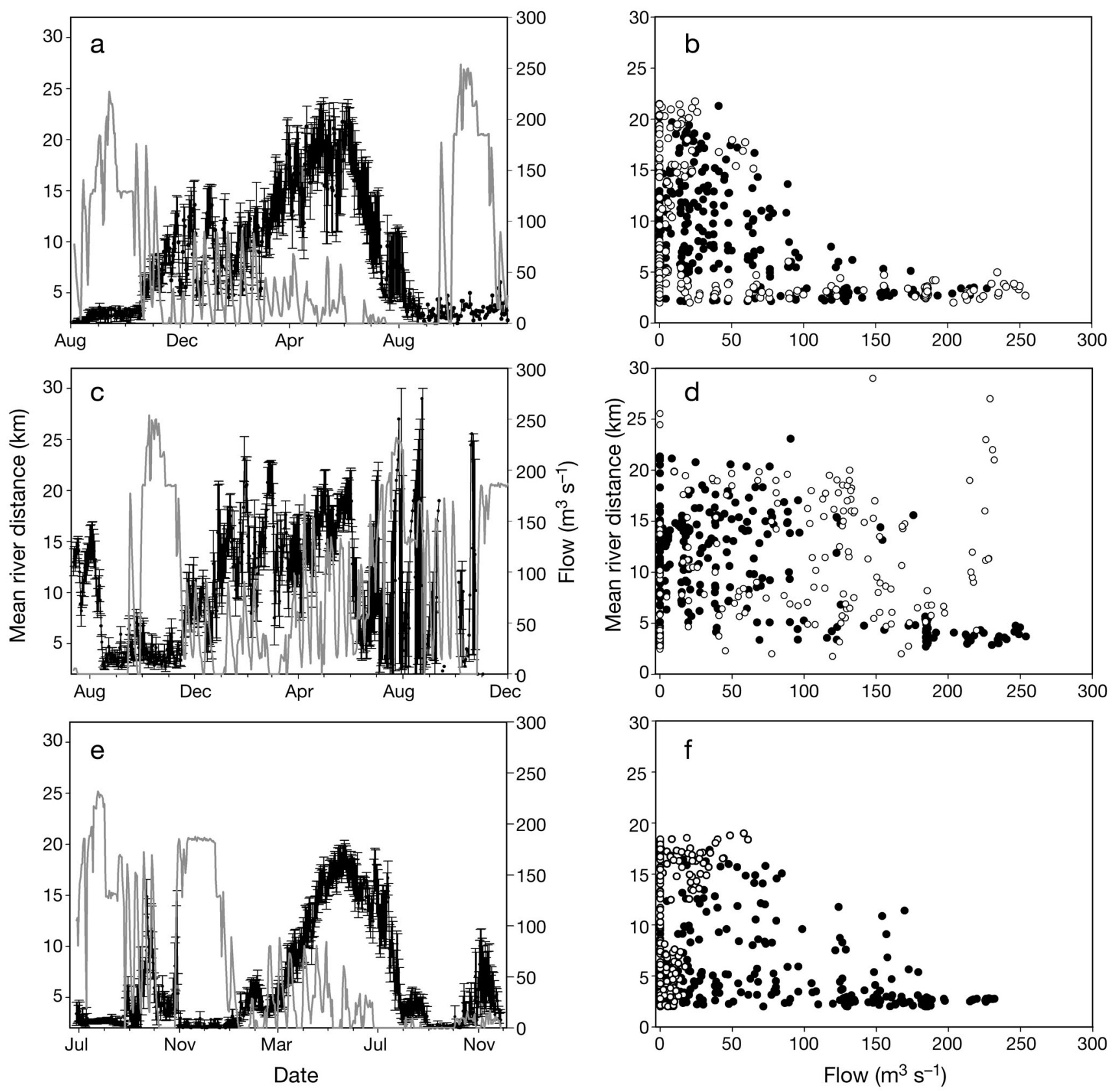

Fig. 6. Carcharhinus leucas. Relationship between freshwater inflow and distribution of acoustically tagged bull sharks from the $(a, b)$ 2003, (c,d) 2004 and (e,f) 2005 cohorts within the Caloosahatchee River estuary. Time series plots (a,c,e) - grey line: freshwater inflow; points (largely hidden by error bars): mean river location; error bars: minimum and maximum extent of a cohort. Scatterplots $(\mathrm{b}, \mathrm{d}, \mathrm{f})$ show daily mean river location and freshwater inflow for sharks $<1 \mathrm{yr}$ old (filled circles) and $>1 \mathrm{yr}$ old (open circles)

salinity tended to result in reduced proportions of sharks present, while periods of low flow and higher salinity had greater proportions present. The pattern of occurrence within the river was different to most other shark nursery areas, where there is a distinct seasonal pattern of occurrence, with the young migrating out of the nursery in response to seasonal changes in temperature or photoperiod (e.g. Grubbs et al. 2007, Heupel 2007).
Previous research on Carcharhinus leucas has suggested that their use of freshwater systems is not based on physiology, but rather is a strategy to take advantage of increased prey resources and decreased predation risk (Pillans \& Franklin 2004, Pillans et al. 2005). Although sharks may exploit these habitats for ecological reasons, there is little information on how habitats are used by young bull sharks. Contrary to suggestions in osmoregulatory studies, results of the present study 

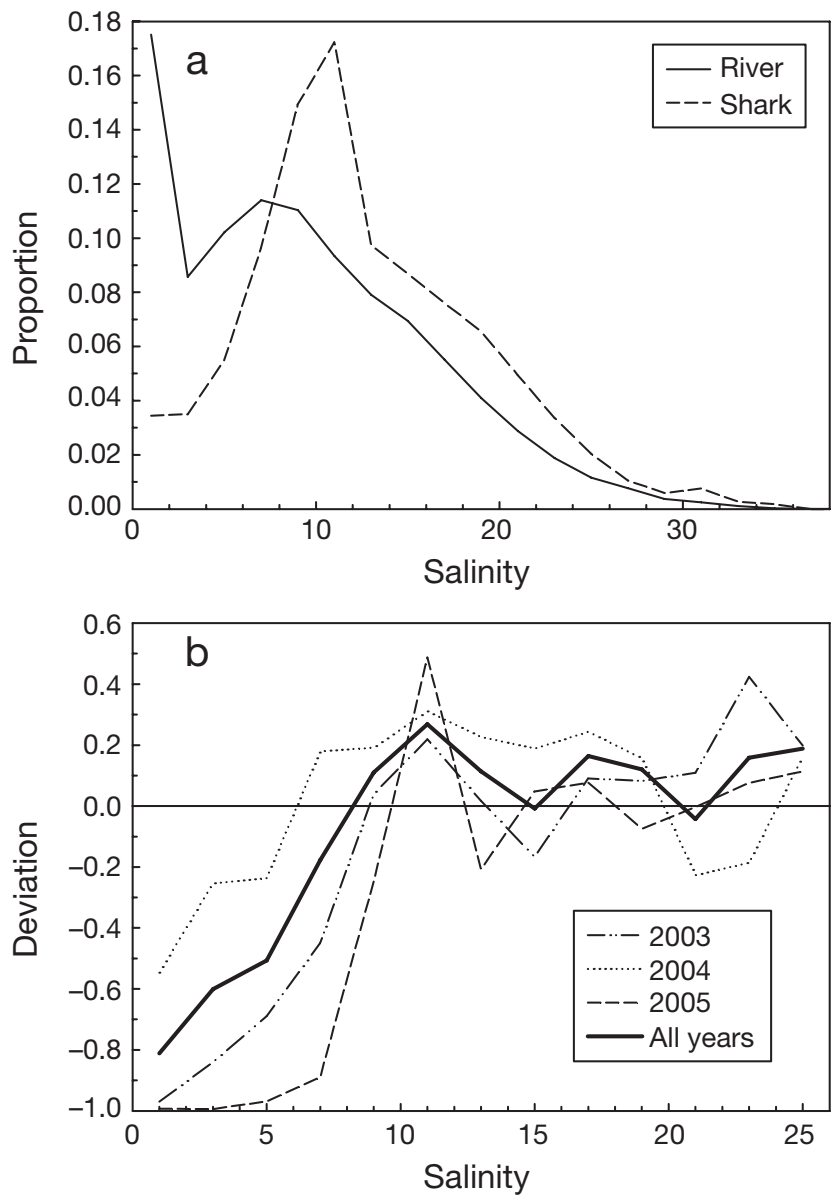

Fig. 7. Carcharhinus leucas. Salinity electivity analysis for bull sharks in the Caloosahatchee River estuary. (a) Proportional occurrence of bull sharks by salinity (dashed line) and corresponding salinity values available within the estuary when sharks were present (solid line). (b) Electivity values standardized by the value of Chesson's $\alpha$; values above zero indicate affinity, values below indicate avoidance

suggest that habitat use within estuary and river systems - especially for the youngest animals $(<1 \mathrm{yr}$ old) — is influenced by environmental variables, and potentially by physiological abilities. While they are capable of osmoregulating over the full range of salinities (Thorson et al. 1973, Pillans et al. 2006), young C. leucas showed consistent salinity preferences, choosing to avoid salinities $<7$ and having an affinity for salinities from 7 to at least 20. Data for salinities $>20$ were scarce; further data collection at high salinities will help understand relationships within that range. Affinity for areas with salinities from 7 to 20 corresponds to the observations of Simpfendorfer et al. (2005), who reported that the highest catch per unit effort of $<1 \mathrm{yr}$ old $C$. leucas individuals within the Caloosahatchee River/Pine Island Sound estuary system was in salinities between 7 and 17.5. Confirma- tion of Simpfendorfer et al.'s results provides further evidence that the distribution of young $C$. leucas within estuarine systems is correlated with salinity. This raises several questions: Are sharks moving in response to changes in salinity because it challenges their physiological capabilities, is it to maintain an optimal physiological/energetic state, or do they move in response to other factors that are correlated with salinity?

\section{Effects of salinity and freshwater inflow}

In other euryhaline teleost species, the energetic cost of osmoregulation varies with salinity (e.g. Rao 1968, Marais 1978, Barton \& Barton 1987), suggesting that the use of salinity-selection behavior is related to energy allocation. These examples suggest that fish use movement to select specific environmental conditions and support the hypothesis that bull sharks may be using habitat within the Caloosahatchee River estuary to maximize energetic benefits. Salinity appeared to most strongly influence the distribution of sharks $<1$ yr old, suggesting that bull sharks become more tolerant of low or high salinity conditions as they age. This is logical for small individuals that have a high surface area to volume ratio and require greater amounts of energy to regulate water and ions if exposed to varying salinities, especially given the importance of urea in the osmoregulatory strategy of sharks. This result is similar to that of Pillans \& Franklin (2004), who found that the smallest Carcharhinus leucas inhabited freshwater regions and larger individuals were in more marine waters. They also suggested that smaller C. leucas are not fully capable of regulating urea and that this may explain their absence from marine environments. This would imply a direct physiological limitation to young C. leucas utilizing marine regions with individuals developing the ability to tolerate those conditions as they age. Observed movement behavior may also suggest that small individuals are avoiding areas of strong current. In either case this result suggests that avoidance of extreme salinity (i.e. below 7 or above 20) or high flow regions is a means of energy conservation or the result of physiological limitation.

Although physiological studies have examined the exposure of Carcharhinus leucas from freshwater to seawater (e.g. Pillans et al. 2006), no current data are available to examine movement from iso-osmotic conditions (presumably at mid range salinity) to freshwater conditions. Based on laboratory studies of a euryhaline teleost, Kidder et al. (2006b) revealed that movement to freshwater would be slightly less stressful than movement into seawater, but that remaining in 
brackish water would be the least stressful of the 3 conditions. This suggests that remaining in iso-osmotic conditions has benefits over either extreme for euryhaline species. Therefore, Kidder et al. (2006b) suggested that behavioral osmoregulation may be a favorable strategy for euryhaline species in some circumstances. Similar laboratory-based research to that conducted by Kidder et al. would elucidate whether these same conclusions apply to C. leucas, and should be considered in future studies. Based on behavioral observations, it appears that movement by $C$. leucas occurs as a result of environmental change and a desire to remain in iso-osmotic conditions.

Although salinity influences the distribution of juvenile bull sharks within the Caloosahatchee River, the correlative nature of the evidence means that another factor (or factors) correlated with salinity may be the mechanism that controls the observed patterns. Within estuarine systems there are many factors that are correlated with salinity. These include physical factors such as freshwater inflow rates, nutrient loads, turbidity and temperature. Two of these factors were examined in this study: freshwater flow rate and temperature.

Temperature data revealed distinct seasonal patterns, with increased temperatures from April to December and decreased temperatures during winter months (January to March). Individuals from 2003 and 2005 cohorts showed no relationship between location and temperature. There was a significant relationship between distribution within the river and temperature for individuals in the 2004 cohort. These contradictory results suggest that temperature plays some role in the movements of young Carcharhinus leucas, although its influence is not be strong enough to be detected in the presence of greater movement cues. Simpfendorfer et al. (2005) demonstrated that temperature was significant in explaining the occurrence of young bull sharks, but only as factor that may control seasonal cycles. The results of the GLM support this conclusion, as month (a factor correlated with temperature) was included in the final model. Although temperature may play some role in $C$. leucas distribution in the Caloosahatchee River estuary, it is most likely seasonal, and does not explain up/down river movements observed within a season.

Freshwater inflow measured at the Franklin Locks at the upper end of the Caloosahatchee River estuary may have influenced the distribution of sharks in 2 ways. (1) Flow rates may have directly acted on sharks and caused movement. Water flow rates in estuarine systems influence the distribution of juvenile sharks: juvenile sandbar sharks Carcharhinus plumbeus move up estuaries on incoming tides and down with outgoing tides (Medved \& Marshall 1983, Wetherbee \&
Rechisky 2000). This passive transport may provide a means of energy conservation for young sharks. (2) Freshwater input may have influenced distribution patterns was via its effect on salinity. Although salinity was correlated with freshwater flow rates measured at the lock, the relationship was not particularly strong, as there was significant inflow from creeks and urban runoff along the estuarine portion of the river during the summer wet season (P. Doering pers. comm.). This runoff can cause pockets of lower salinity water that are not directly related to river flow rate, but may affect shark distribution patterns. The presence of runoff means that flow rate from the lock may not directly affect shark movements, but changes in salinity based on all aspects of freshwater input may be a more likely cause. This was supported by results of the GLM, which incorporated both salinity and flow in the model predicting shark location. If freshwater flow were the only driver of salinity, then only one factor would have been incorporated into the model.

Separation of correlating factors from salinity and flow was not possible in this analysis and so it is unknown if other parameters such as turbidity or $\mathrm{pH}$ also played a role in shark movements and distribution. An additional consideration which could not be tested in this study is whether shark movement was related to the movement of prey species. If prey species are intolerant to environmental change and forced toward the river mouth during high flow/low salinity conditions, shark behavior may have mirrored that of their prey. However, bull sharks feed on a wide array of prey items including freshwater species (Snelson et al. 1984), so that movement down river would not be necessary, since freshwater prey species would still be present farther up river. Given the broad nature of the diet of Carcharhinus leucas, it is unlikely that redistribution of stenohaline prey would be sufficient to force movement of the entire population toward the river mouth when freshwater or euryhaline prey were still present. Most shark species do not feed continuously, so immediate and continuous movement to regions with high prey abundance would not be necessary. In this scenario sharks could move toward the mouth to find prey and resume use of the remainder of the estuary, resulting in no obvious pattern with changing environmental condition. Instead, all monitored individuals moved toward the mouth of the river when salinity declined and remained there until salinity returned to more mesohaline conditions. Although following prey down river cannot be ruled out as a cause for the observed behavior, it is unlikely, but was impossible to test in the present study. Further research should be conducted to examine this relationship.

Data presented in this study reveal the locations of individual Carcharhinus leucas for periods of up to 
18 mo. Although these data cover a long time series, it was somewhat difficult to compare results across years based on differences in environmental conditions and salinity regime. Salinity and flow regimes in 2003 and 2005 were typical of the pattern observed in this region in most years. Salinity levels were low during the months of August to December, as flow from Lake Okeechobee was increased during the hurricane season. Rainfall was high during this period, also causing increased terrestrial runoff into the river, and combined with releases from the lake resulted in large flow spikes into the estuary. From March to July flow through the dam decreased due to the end of the rainy season. Lack of rainfall during this period also decreased terrestrial runoff, allowing the river to become better mixed and tidally influenced. During 2004 the salinity regime within the river was more erratic, and salinity levels typically did not get as high as they did in other years. This was due to an alteration in water management practice. During 2004 an attempt was made to lower water levels in Lake Okeechobee, which resulted in a different flow regime than in other years. For example, large releases were observed from April through August and into December in 2004, and sharks spent more time in the lower reaches of the river, where tidal influence was greatest and salinity higher. This pattern was similar to that in 2003 and 2005, when sharks moved toward the mouth when salinity declines occurred. Although data across years were different, similar general movement and distribution patterns occurred and all individuals monitored appeared to be affected in the same way.

Although bull sharks penetrate freshwater systems (e.g. Thomerson et al. 1977, Pillans \& Franklin 2004), results of this research suggest that youngest individuals preferred moderate salinity levels, presumably in an effort to increase energy allocation to growth or other functions by reducing osmoregulatory costs. This is the first study to suggest that this highly mobile species may use movement to compensate for salinity change, and we suggest that the observed data are the result of behavioral osmoregulation via movement.

Acknowledgements. We thank A. Collins and B. Yeiser for their assistance with data collection, handling and equipment maintenance. We also thank numerous volunteer student interns for their assistance during this project. This research was funded in part by the Mote Scientific Foundation and the National Shark Research Consortium (NOAA Fisheries). P. Doering and K. Haunert from the SFWMD provided information on the Caloosahatchee River system and access to water quality data. Treatment of all animals in this study was conducted under ethical guidelines and approval for procedures was granted to M.R.H. by the MML IACUC Committee.

\section{LITERATURE CITED}

Ackerman JT, Kondratieff MC, Matern SA, Cech JJ Jr (2000) Tidal influence on spatial dynamics of leopard sharks, Triakis semifasciata, in Tomales Bay, California. Environ Biol Fishes 58:33-43

Akaike H (1973) Information theory and an extension of the maximum likelihood principle. In: Petrov BN, Csaki F (eds) 2nd Int Symp on Inf Theory, Akademiai Kaido, Budapest

Barton M, Barton AC (1987) Effects of salinity on oxygen consumption of Cyprinodon variegates. Copeia 1987:230-232

Bass AJ, D'Aubrey JD, Kistnasamy N (1973) Sharks of the east coast of southern Africa. 1. The genus Carcharhinus (Carcharhinidae). Investigational Report 33, Oceanographic Research Institute, Durban

Cheng W, Yeh SP, Wang CS, Chen JC (2002) Osmotic and ionic changes in Taiwan abalone Haliotis diversicolor supertexta at different salinity levels. Aquaculture 203: 349-357

Chesson J (1978) Measuring preference in selective predation. Ecology 59:211-215

Doering PH, Chamberlain RH (1998) Water quality in the Caloosahatchee Estuary, San Carlos Bay and Pine Island Sound. In: Proc Charlotte Harbor Public Conf Tech Symp, Tech Rep No. 98-02, Charlotte Harbor National Estuary Program, Punta Gorda, FL, p 229-240

Evans DH (1997) The physiology of fishes. CRC Press, Boca Raton, FL

Flaig EG, Capece J (1998) Water use and runoff in the Caloosahatchee watershed. In: Proc Charlotte Harbor Public Conf Tech Symp, Tech Rep No. 98-02, Charlotte Harbor National Estuary Program, Punta Gorda, FL, p 73-80

Grubbs RD, Musick JA, Conrath CL, Romine JG (2007) Longterm movements, migrations, and temporal delineation of a summer nursery for juvenile sandbar sharks in the Chesapeake Bay region. In: McCandless CT, Pratt HL Jr, Kohler NE (eds) Shark nursery grounds of the Gulf of Mexico and East Coast waters of the United States. Am Fish Soc Symp 50:63-86

Heupel MR (2007) Exiting Terra Ceia Bay: examination of cues stimulating migration from a summer nursery area. In: McCandless CT, Pratt HL Jr, Kohler NE (eds) Shark nursery grounds of the Gulf of Mexico and East Coast waters of the United States. Am Fish Soc Symp 50: $265-280$

Heupel MR, Hueter RE (2001) Use of a remote acoustic telemetry system to monitor shark movements in a coastal nursery area. In: Sibert JR, Nielsen JL (eds) Electronic tagging and tracking in marine fisheries. Kluwer, Dordrecht, p 217-236

Kidder GW III (1997) Behavioral osmoregulation in Fundulus heteroclitus. Bull Mt Desert Isl Biol Lab 36:69

Kidder GW III, Petersen CW, Preston RL (2006a) Energetics of osmoregulation: I. Oxygen consumption by Fundulus heteroclitus. J Exp Zool 305A:309-317

Kidder GW III, Petersen CW, Preston RL (2006b) Energetics of osmoregulation: II. Water flux and osmoregulatory work in the euryhaline fish, Fundulus heteroclitus. J Exp Zool 305A:318-327

Maetz J (1974) Aspects of adaptation to hypo-osmotic and hyper-osmotic environments. In: Malins DC, Sargent JR (eds) Biochemical and biophysical perspectives in marine biology. Academic Press, London, p 1-167

Marais JFK (1978) Routine oxygen consumption of Mugil cephalus, Liza dumerili and L. richardsoni at different temperatures and salinities. Mar Biol 50:9-16

Matern SA, Cech JJ Jr, Hopkins TE (2000) Diel movements of 
bat rays, Myliobatis californica, in Tomales Bay, California: evidence for behavioral thermoregulation? Environ Biol Fishes 58:173-182

Medved RJ, Marshall JA (1983) Short-term movements of young sandbar sharks, Carcharhinus plumbeus (Pisces, Carcharhinidae). Bull Mar Sci 33:87-93

Montoya RV, Thorson TB (1982) The bull shark (Carcharhinus leucas) and largetooth sawfish (Pristis perotteti) in Lake Bayano, a tropical man-made impoundment in Panama. Environ Biol Fishes 7:341-347

> Piermarini PM, Evans DH (1998) Osmoregulation of the Atlantic stingray (Dasyatis sabina) from the freshwater Lake Jesup of the St. Johns River, Florida. Physiol Zool 71: 553-560

Pillans RD, Franklin CE (2004) Plasma osmolyte concentrations and rectal gland mass of bull sharks Carcharhinus leucas, captured along a salinity gradient. Comp Biochem Physiol A 138:363-371

Pillans RD, Good JP, Anderson WG, Hazon N, Franklin CE (2005) Freshwater to seawater acclimation of juvenile bull sharks (Carcharhinus leucas): plasma osmolytes and $\mathrm{Na}^{+} / \mathrm{K}^{+}$-ATPase activity in gill, rectal gland, kidney and intestine. J Comp Physiol B 175:37-44

Pillans RD, Anderson WG, Good JP, Hyodo S, Takei Y, Hazon N, Franklin CE (2006) plasma and erythrocyte solute properties of juvenile bull sharks, Carcharhinus leucas, acutely exposed to increasing environmental salinity. J Exp Mar Biol Ecol 331:145-157

Rao GMN (1968) Oxygen consumption of rainbow trout (Salmo gardneri) in relation to activity and salinity. Can J Zool 46:781-786

SFWMD (2000) Caloosahatchee Water Management Plan. South Florida Water Management District, West Palm Beach, FL

Simpfendorfer CA, Freitas GG, Wiley TR, Heupel MR (2005)

Initial editorial responsibility: Howard Browman,

Storebø, Norway

Final editorial responsibility: Matthias Seaman,

Oldendorf/Luhe, Germany
Distribution and habitat partitioning of immature bull sharks (Carcharhinus leucas) in a southwest Florida estuary. Estuaries 28:78-85

Simpfendorfer CA, Heupel MR, Collins AB (in press) Variation in the efficiency of acoustic receivers and its implication for positioning algorithms in a riverine setting. Can J Fish Aquat Sci

Snelson FF Jr, Mulligan TJ, Williams SE (1984) Food habits, occurrence, and population structure of the bull shark, Carcharhinus leucas, in Florida coastal lagoons. Bull Mar Sci 34:71-80

Stucchi-Zucchi A, Salomao LC (1998) The ionic basis of membrane potentials and adaptation to hyposmotic stress in Perna perna, an osmoconforming mollusk. Comp Biochem Physiol A 121:143-148

Taniuchi T, Shimuzu M, Sano M, Baba O, Last PR (1991) Description of freshwater elasmobranchs collected from 3 rivers in northern Australia. In: Shimizu M, Taniuchi T (eds) Studies on elasmobranchs collected from seven river systems in northern Australia and Papua New Guinea, Vol 3. The University Museum, the University of Tokyo, Nature and Culture, Tokyo, p 11-26

Thomerson JE, Thorson TB, Hempel RL (1977) The bull shark, Carcharhinus leucas, from the upper Mississippi River near Alton, Illinois. Copeia 1977:166-168

Thorson TB, Cowan CM, Watson DE (1973) Body fluid solutes of juveniles and adults of the euryhaline bull shark Carcharhinus leucas from freshwater and saline environments. Physiol Zool 46:29-42

Wetherbee BM, Rechisky EL (2000) Movement patterns of juvenile sandbar sharks on their nursery grounds in Delaware Bay. In: Eiler JH, Alcorn DJ, Neuman MR (eds) Biotelemetry 15: Proc 15th Int Symp on Biotelemetry. Juneau, AK. International Society on Biotelemetry, Wagenigen, p 91-98

Submitted: August 21, 2007; Accepted: January 3, 2008 Proofs received from author(s): January 31, 2008 